\title{
Cilostazol for secondary stroke prevention: systematic review and meta- analysis
}

\author{
Choon Han Tan (D) , ${ }^{1}$ Andrew GR Wu, ${ }^{2}$ Ching-Hui Sia (D) , ${ }^{3}$ Aloysius ST Leow (D) , \\ Bernard PL Chan, ${ }^{4}$ Vijay Kumar Sharma (D) , ${ }^{2,4}$ Leonard LL Yeo (D) , 2,4 \\ Benjamin YQ Tan (D) 2,4
}

To cite: Tan $\mathrm{CH}$, Wu AGR, Sia C-H, et al. Cilostazol for secondary stroke prevention: systematic review and metaanalysis. Stroke \& Vascular Neurology 2021;6: e000737. doi:10.1136/svn-2020-000737

- Additional material is published online only. To view, please visit the journal online (http://dx.doi.org/10.1136/svn2020-000737).

\section{CHT and AGW are joint first} authors.

Received 5 November 2020 Accepted 1 December 2020 Published Online First 4 February 2021

\section{Check for updates}

(c) Author(s) (or their employer(s)) 2021. Re-use permitted under CC BY-NC. No commercial re-use. See rights and permissions. Published by BMJ.

${ }^{1}$ Department of Medicine, Lee Kong Chian School of Medicine, Nanyang Technological University, Singapore

${ }^{2}$ Department of Medicine, Yong Loo Lin School of Medicine, National University of Singapore, Singapore

${ }^{3}$ Department of Cardiology, National University Heart Centre, Singapore

${ }^{4}$ Division of Neurology, Department of Medicine, National University Health System, Singapore

Correspondence to Dr Leonard LL Yeo; leonard_II_yeo@nuhs.edu.sg

\section{ABSTRACT}

Background Stroke is one of the leading causes of death worldwide. Cilostazol, an antiplatelet and phosphodiesterase 3 inhibitor, has not been clearly established for ischaemic stroke use. We aim to determine the efficacy and safety of cilostazol for secondary stroke prevention.

Methods MEDLINE, EMBASE, Cochrane Library, Web of Science and ClinicalTrials. gov were searched from inception to 25 September 2020, for randomised trials comparing the efficacy and safety of cilostazol monotherapy or dual therapy with another antiplatelet regimen or placebo, in patients with ischaemic stroke. Version 2 of the Cochrane risk-of-bias tool for randomised trials (RoB 2) was used to assess study quality. This metaanalysis was reported in line with the Preferred Reporting Items for Systematic Reviews and Meta-Analyses (PRISMA) statement.

Results Eighteen randomised trials comprising 11429 participants were included in this meta-analysis. Most trials possessed low risk of bias and were of low heterogeneity. Cilostazol significantly reduced the rate of ischaemic stroke recurrence (risk ratio, $\mathrm{RR}=0.69,95 \% \mathrm{Cl} 0.58$ to 0.81 ), any stroke recurrence ( $\mathrm{RR}=0.64,95 \% \mathrm{Cl} 0.54$ to 0.74$)$ and major adverse cardiovascular events ( $\mathrm{RR}=0.67,95 \% \mathrm{Cl}$ 0.56 to 0.81 ). Cilostazol did not significantly decrease mortality ( $R R=0.90,95 \% \mathrm{Cl} 0.64$ to 1.25$)$ or increase the rate of good functional outcome (Modified Rankin Scale score of $0-1 ; \mathrm{RR}=1.07,95 \% \mathrm{Cl} 0.95$ to 1.19). Cilostazol demonstrated favourable safety profile, significantly reducing the risk of intracranial haemorrhage $(R R=0.46$, $95 \% \mathrm{Cl} 0.31$ to 0.68 ) and major haemorrhagic events ( $R R=0.49,95 \% \mathrm{Cl} 0.34$ to 0.70 ).

Conclusions Cilostazol demonstrated superior efficacy and safety profiles compared with traditional antiplatelet regimens such as aspirin and clopidogrel for secondary stroke prevention but does not appear to affect functional outcomes. Future randomised trials can be conducted outside East Asia, or compare cilostazol with a wider range of antiplatelet agents.

\section{BACKGROUND}

\section{Introduction}

The rate of ischaemic stroke recurrence varies from $8 \%-14 \%$ at 1 year to $39 \%$ at 10 years, ${ }^{12}$ and is associated with poor outcomes. ${ }^{3}$ To reduce the recurrence of ischaemic strokes, antiplatelet therapies are widely adopted. Some established regimens include single antiplatelet therapy with aspirin, ${ }^{4}$ monotherapy with clopidogrel $l^{5}$ and combination aspirin and extended-release dipyridamole. ${ }^{6}$ Aspirin and clopidogrel combination can be considered for short-term stroke management. However, these antiplatelet therapies, especially long-term combination aspirin and clopidogrel, are known to increase the risk of haemorrhagic conversion and bleeding complications. ${ }^{78}$

Cilostazol is an approved treatment for intermittent claudication and thrombotic complications of coronary angioplasty in combination with aspirin or clopidogrel. ${ }^{9}$ It selectively inhibits phosphodiesterase 3, increasing activation of intracellular cyclic adenosine monophosphate and protein kinase A, thereby inhibiting platelet aggregation. Apart from its antiplatelet properties, cilostazol may prevent recurrent ischaemic stroke by improving endothelial function, ${ }^{10}$ reducing triglycerides and increasing highdensity lipoproteins. ${ }^{11}$ The Chinese Guidelines for Secondary Prevention of Ischemic Stroke and Transient Ischemic Attack, Korean Clinical Practice Guidelines for Stroke, Japanese Guidelines for the Management of Stroke and other eastern institutions ${ }^{12-15}$ have accepted cilostazol as a second-line drug to aspirin and/or clopidogrel for secondary stroke prevention. However, cilostazol is neither widely recommended nor approved by most international guidelines. ${ }^{4}$

\section{Objectives}

Cilostazol is an accepted monotherapy for secondary stroke prevention in East Asian countries but is not commonly used outside Asia. Previous meta-analyses have also demonstrated the efficacy and safety of cilostazol to this end. ${ }^{16-18}$ However, those reviews do not include a new randomised trial evaluating the short-term use of cilostazol in acute ischaemic 
stroke. Since studies performed on these subgroups are relatively scarce, it is useful to perform an updated metaanalysis to (1) confirm the effect of cilostazol as monotherapy; and (2) explore the effect of cilostazol in combination therapy. To investigate the efficacy of cilostazol-based therapies in different situations, we performed subgroup analyses on intracranial arterial stenosis (ICAS), specific antiplatelet regimens, stroke chronicity and duration of treatment. Unlike previous meta-analyses, we graded the quality of evidence for each outcome measure.

\section{METHODS}

\section{Search strategy}

We report the findings according to the Preferred Reporting Items for Systematic Reviews and MetaAnalyses (PRISMA) statement. ${ }^{19}$ The authors screened multiple comprehensive databases (MEDLINE, EMBASE, Cochrane Library, Web of Science and ClinicalTrials.gov) for studies comparing cilostazol and other antiplatelet regimens for secondary prevention of ischaemic stroke.

The literature search was conducted for all publications in the databases from inception to 25 September 2020. We used keywords related to stroke (eg, 'stroke', 'cerebrovascular accident' or 'cerebral infarct') and cilostazol (eg, 'cilostazol', 'Pletal' or 'phosphodiesterase 3 inhibitor'). Medical Subject Headings (MeSH) and EMBASE subject headings (EMTREE) terms were used in conjunction with keywords to refine the search results (online supplemental data). Manual searches were also conducted on the reference lists of included studies and review articles to identify trials that were missed in the electronic search.

\section{Study selection}

The inclusion criteria encompassed any randomised trials that compared the efficacy and safety of cilostazol used as monotherapy or combination therapy with other antiplatelet agents, placebo or best medical therapy for the secondary prevention of ischaemic stroke. Nonrandomised observational studies and conference proceedings were excluded.

The primary clinical outcome was ischaemic stroke recurrence. Safety outcomes comprised intracranial haemorrhages $(\mathrm{ICH})$ and major haemorrhagic events. Secondary outcomes included any stroke recurrence, all-cause mortality, major adverse cardiovascular events (MACE) and adverse drug events (ADEs) leading to treatment discontinuation. Most studies defined ICH as intracerebral haemorrhage or subarachnoid haemorrhage. The definition for 'any stroke' comprised ischaemic stroke and either haemorrhagic stroke or ICH but did not include transient ischaemic attacks. Good functional outcome was defined as a Modified Rankin Scale score of $0-1$ (mRS 0-1) at 3-6 months.

Two reviewers (TCH and WGRA) independently performed title and abstract screening on studies retrieved from the search strategy, followed by full-text screening. Data extraction and quality assessment were performed independently. Any disagreements were resolved by consensus.

\section{Data collection}

The predesigned data extraction form included the following: (1) intervention and control; (2) participant characteristics, for example, age, National Institutes of Health Stroke Scale (NIHSS) on admission and country of study; (3) stroke subtypes; (4) time to randomisation or treatment; (5) duration of treatment and follow-up; and (6) outcome event rates.

\section{Quality assessment}

Quality assessment of the included studies was performed using Version 2 of the Cochrane tool for assessing risk of bias in randomised trials (RoB 2) ${ }^{20}$ For each included study, signalling questions were answered to assess the risk of bias arising from: (1) the randomisation process; (2) deviations from the intended interventions; (3) missing outcome data; (4) the measurement of outcomes; and (5) the selection of reported results. Each component was individually assessed as having low, some concerns or high risk of bias.

The quality of evidence for each outcome was determined using the Grading of Recommendations Assessment, Development and Evaluation (GRADE) system consisting of five components: risk of bias, imprecision, inconsistency, indirectness and publication bias. ${ }^{21}$

\section{Statistical analysis}

The random-effects model was used to generate risk ratios (RRs) and associated $95 \%$ CIs. Where possible, the intention-to-treat (ITT) population was used. Heterogeneity was evaluated using the chi square $\left(\chi^{2}\right)$ and $\mathrm{I}^{2}$ test. $\mathrm{I}^{2}<25 \%, 25 \%-75 \%$ and $>75 \%$ indicated low, moderate and high degree of inconsistency, respectively. Metaregression was performed using the mixed-effects model. Publication bias was assessed using funnel plots. A p value $\leq 0.05$ was considered statistically significant. All analyses were performed using Review Manger V.5.3 (The Cochrane Collaboration, 2014) and meta package V.4.13-0 in R (R Foundation for Statistical Computing, Vienna, Austria).

\section{RESULTS}

\section{Study selection and study characteristics}

A total of 2415 unique records were retrieved. Of these, the full text of 81 studies were screened (online supplemental data).

We included 18 randomised trials comprising 11429 patients in the ITT population ${ }^{22-39}$ (tables 1 and 2). Nine studies were conducted in Japan, four in Korea, two in China, two in multiple East Asian countries and one in the UK. Most studies explicitly excluded patients with cardioembolic stroke, but two studies ${ }^{23} 33$ did not specify this. Three studies ${ }^{30} 3139$ recruited participants with symptomatic ICAS, while two studies ${ }^{23}{ }^{26}$ included patients with lacunar infarction. Although one study 


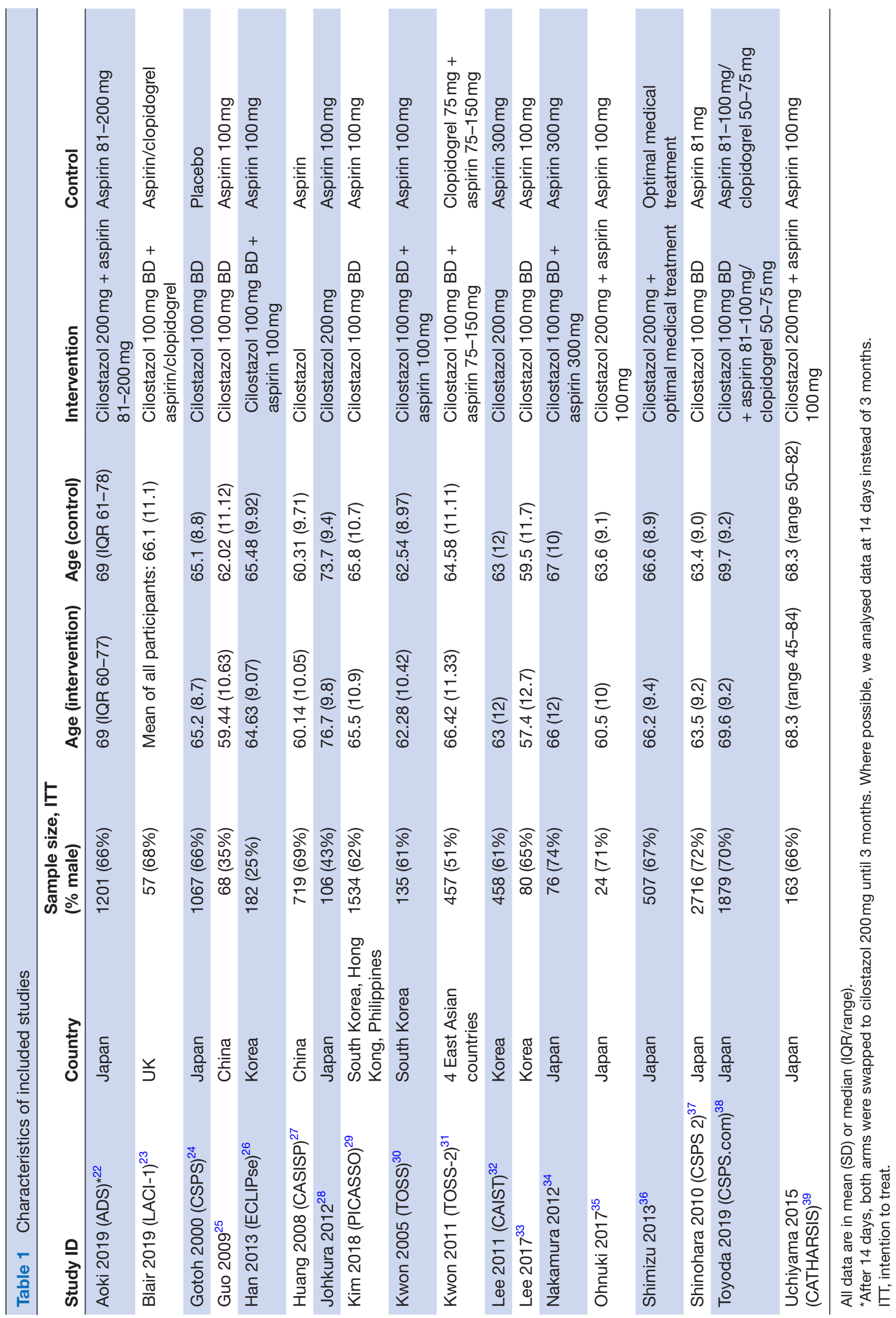




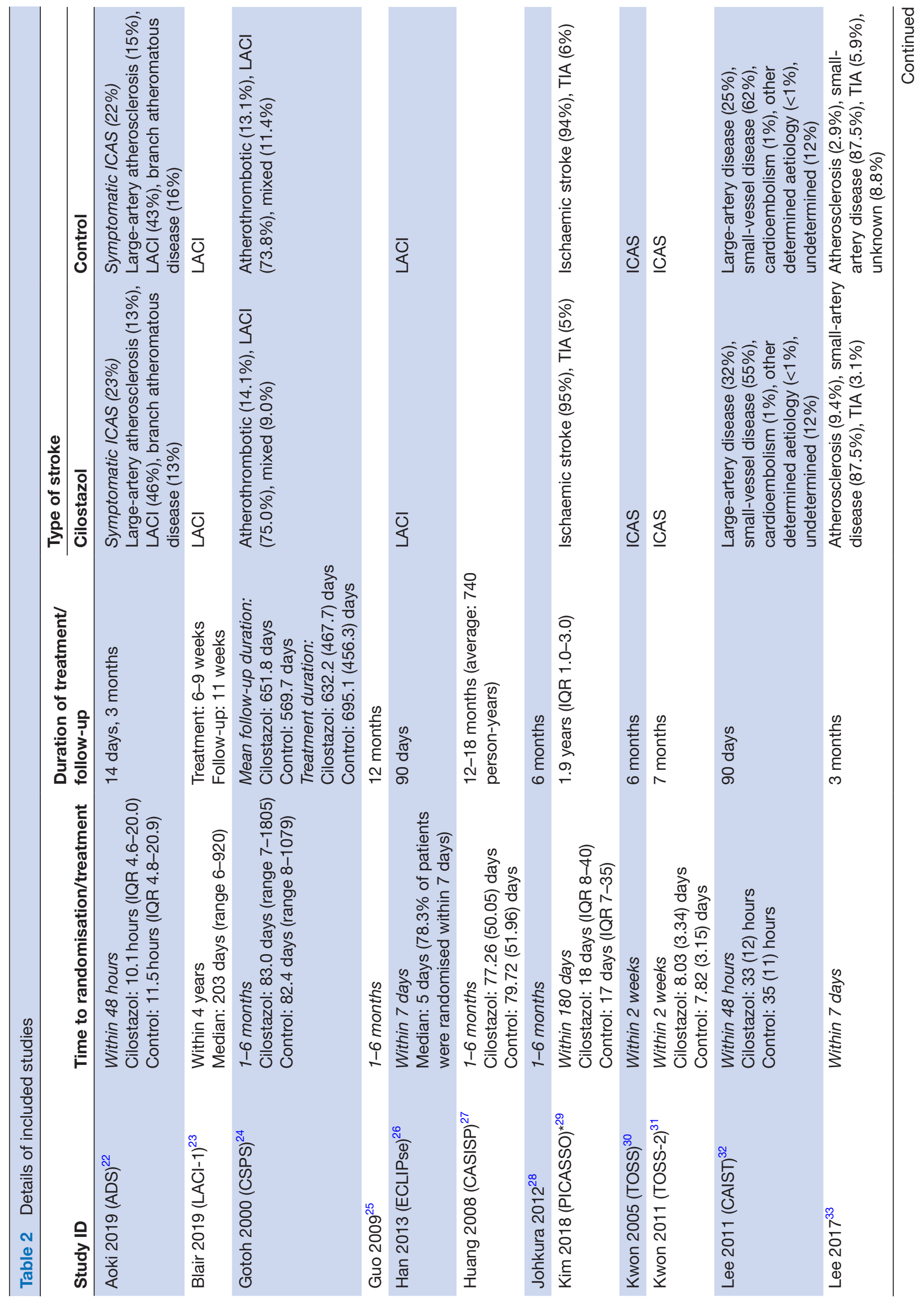




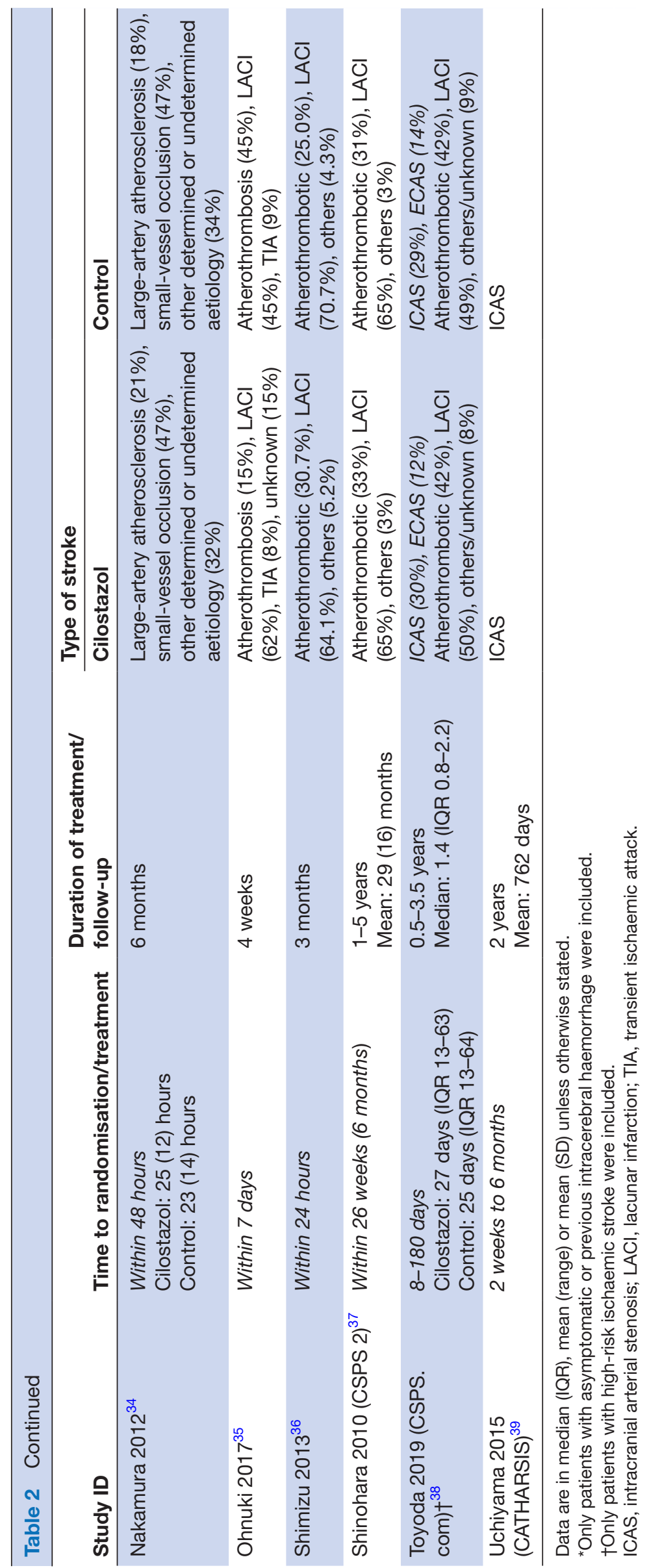


recruited only patients with asymptomatic or previous intracerebral haemorrhage, ${ }^{29}$ most studies excluded such patients or participants with a bleeding diathesis. One study included patients with high-risk ischaemic stroke,$^{38}$ while most others did not include patients with moderate-to-severe disability, for example, NIHSS $\geq 8,{ }^{34}$ NIHSS $\geq 16^{253032}$ or NIHSS $\geq 20^{2236}$, mRS $\geq 4^{2527}$ or severe cerebral deficits. ${ }^{23}{ }^{24}$ Some studies explicitly excluded patients with concurrent antiplatelet, ${ }^{22} 24$ 26-28 3032 33 37-39 anticoagulant, ${ }^{22-24} 263032-3437-39$ or thrombolytic/fibrinolytic $2431-343637$ use.

Four trials ${ }^{22} 323436$ included patients with acute stroke (onset within 48 hours); three trials ${ }^{22} 2335$ administered short-term antiplatelet therapy ( $<3$ months). Studies compared cilostazol (CIL) single or dual antiplatelet therapy (SAPT or DAPT) against aspirin (ASA), clopidogrel (CLO), and placebo or best medical therapy (No CIL). For one study, ${ }^{22}$ we analysed data recorded at 14 days instead of 3 months if available-that is, for most outcomes except for major haemorrhagic events and good functional outcome-to minimise bias from the treatment regimen.

\section{Quality assessment}

On the basis of RoB 2, most trials were of high quality and possessed a low overall risk of bias (online supplemental data). One trial ${ }^{28}$ had a high risk of bias due to missing outcome data from a significant, asymmetric loss to follow-up.

\section{Stroke recurrence and functional outcomes \\ Ischaemic stroke recurrence}

Meta-analysis of all 18 randomised trials (figure 1) revealed cilostazol significantly reduced the risk of recurrent ischaemic stroke ( $\mathrm{RR}=0.69,95 \%$ CI 0.58 to 0.81 , $\mathrm{p}<0.0001)$. There was low heterogeneity across all trials $\left(\mathrm{I}^{2}=0 \%\right)$.

Subgroup analysis based on specific antiplatelet regimens indicated moderate heterogeneity between antiplatelet regimens $\left(\mathrm{I}^{2}=42.9 \% ; \quad \chi_{5}^{2}=8.76, \mathrm{p}=0.12\right)$. The greatest risk reduction was as follows: (1) CIL+CLOversus CLO ( $\mathrm{n}=1116)$; followed by (2) CIL versus no CIL $(\mathrm{n}=1574)$; (3) CIL+ASA versus ASA $(\mathrm{n}=2544)$; and (4) CIL versus ASA ( $\mathrm{n}=5681)$. Interestingly, CIL+ASA performed worse than ASA+CLO, although this effect was not statistically significant $(n=457 ; R R=1.62,95 \%$ CI 0.60 to 4.37 , $\mathrm{p}=0.34$ ). When the specific type of antiplatelet was disregarded, cilostazol DAPT had a greater risk reduction than cilostazol SAPT, both compared with an SAPT.

\section{Any stroke recurrence}

Meta-analysis of all 18 trials (figure 2) revealed cilostazol significantly reduced the recurrence of any stroke, both ischaemic and haemorrhagic ( $\mathrm{RR}=0.64,95 \% \mathrm{CI} 0.54$ to $0.74, \mathrm{p}<0.00001)$. There was low heterogeneity across all trials $\left(\mathrm{I}^{2}=0 \%\right)$.

Subgroup analysis based on specific antiplatelet regimens indicated moderate heterogeneity between antiplatelet regimens $\left(\mathrm{I}^{2}=39.4 \% ; \chi_{4}{ }^{2}=6.61, \mathrm{p}=0.16\right)$. The greatest risk reduction was as follows: (1) CIL+ASA/CLO versus ASA/CLO ( $\mathrm{n}=1936)$; followed by (2) CIL versus no CIL ( $\mathrm{n}=1574)$; and (3) CIL versus ASA $(\mathrm{n}=5681)$. Similar to ischaemic stroke recurrence, CIL+ASA conferred an insignificant increase in risk of any stroke recurrence compared with ASA+CLO $(\mathrm{n}=457 ; \mathrm{RR}=1.78,95 \%$ CI 0.67 to 4.73 , $\mathrm{p}=0.25$ ). However, unlike ischaemic stroke recurrence, CIL+ASA versus ASA did not entail a significant risk reduction for any stroke recurrence $(\mathrm{p}=0.30)$, which can be explained by the smaller sample size.

\section{Intracranial haemorrhage}

Meta-analysis of all 18 trials (figure 3) revealed cilostazol significantly reduced the risk of $\mathrm{ICH}(\mathrm{RR}=0.46,95 \% \mathrm{CI}$ 0.31 to $0.68, \mathrm{p}<0.0001)$. There was low heterogeneity across all trials $\left(\mathrm{I}^{2}=0 \%\right)$.

Subgroup analysis of specific antiplatelet therapies indicated a substantial reduction in risk of ICH when cilostazol monotherapy was compared with aspirin $(\mathrm{RR}=0.36,95 \% \mathrm{CI} 0.22$ to $0.59, \mathrm{p}<0.0001)$. The addition of cilostazol to aspirin or clopidogrel did not significantly affect the risk of ICH.

\section{Functional outcome}

Meta-analysis of four trials (online supplemental data) showed cilostazol did not significantly increase the probability of a good functional outcome ( $\mathrm{RR}=1.07,95 \% \mathrm{CI}$ 0.95 to $1.19, \mathrm{p}=0.28)$. There was moderate heterogeneity among trials $\left(\mathrm{I}^{2}=60 \% ; \chi_{3}{ }^{2}=7.49, \mathrm{p}=0.06\right)$. One trial $^{34}$ contributed significantly to the heterogeneity $(\mathrm{n}=76$; RR=2.00, 95\% CI 1.22 to 3.27$)$; this trial measured patients' mRS scores at 6 months compared with 3 months for the other trials. After removing this trial, $\mathrm{I}^{2}$ decreased to $0 \%$ and $\chi_{2}{ }^{2}=0.71(\mathrm{p}=0.70)$.

\section{Adverse events and mortality}

Major haemorrhagic events

Meta-analysis of 14 trials (figure 4) revealed cilostazol reduced the risk of major haemorrhagic events, which included ICH ( $R R=0.49,95 \%$ CI 0.34 to $0.70, p<0.0001)$. There was low heterogeneity across studies $\left(\mathrm{I}^{2}=0 \%\right)$.

Similar to ICH, cilostazol monotherapy substantially reduced the risk of major haemorrhagic events compared with aspirin ( $R R=0.39,95 \% \mathrm{CI} 0.25$ to $0.62, \mathrm{p}<0.0001$ ), and the addition of cilostazol to aspirin or clopidogrel did not affect the risk of major haemorrhagic events.

\section{Mortality}

Meta-analysis of 15 trials (figure 5) revealed cilostazol did not significantly reduce the risk of mortality $(R R=0.90$, $95 \%$ CI 0.64 to $1.25, \mathrm{p}=0.53$ ). Two trials ${ }^{3132}$ presented data on vascular deaths instead of all-cause mortality. There was low heterogeneity across studies $\left(I^{2}=0 \%\right)$. There was no significant difference between antiplatelet regimens $\left(\mathrm{I}^{2}=0 \% ; \chi_{4}^{2}=0.32, \mathrm{p}=0.99\right)$; there was no statistically significant reduction in mortality for both cilostazol combination therapy and monotherapy. 
Cilostazol Control

Risk Ratio

Study or Subgroup Events Total Events Total Weight M-H, Random, 95\% C 1.1.1 CIL vs ASA

$\begin{array}{lrrrrrr}\text { Guo 2009 } & 2 & 34 & 1 & 34 & 0.5 \% & 2.00[0.19,21.03] \\ \text { Huang 2008 } & 11 & 360 & 15 & 359 & 4.9 \% & 0.73[0.34,1.57] \\ \text { Johkura 2012 } & 0 & 57 & 0 & 49 & & \text { Not estimable } \\ \text { Kim 2018 } & 40 & 766 & 55 & 768 & 18.5 \% & 0.73[0.49,1.08] \\ \text { Lee 2011 } & 5 & 231 & 9 & 227 & 2.5 \% & 0.55[0.19,1.60] \\ \text { Lee 2017 } & 1 & 40 & 0 & 40 & 0.3 \% & 3.00[0.13,71.51] \\ \text { Shinohara 2010 } & 72 & 1356 & 88 & 1360 & 31.5 \% & 0.82[0.61,1.11] \\ \text { Subtotal (95\% Cl) } & & \mathbf{2 8 4 4} & & \mathbf{2 8 3 7} & \mathbf{5 8 . 2 \%} & \mathbf{0 . 7 8}[\mathbf{0 . 6 2}, \mathbf{0 . 9 7}] \\ \text { Total events } & 131 & & 168 & & & \end{array}$

$\begin{array}{lcc}\text { Total events } & 131 & 168 \\ \text { Heterogeneity: } \mathrm{Tau}^{2}=0.00 ; \mathrm{Chi}^{2}=1.98, \mathrm{df}=5(\mathrm{P}=0.85) ; \mathrm{I}^{2}=0 \%\end{array}$

Test for overall effect: $Z=2.19(P=0.03)$

1.1.2 CIL+ASA vs ASA

$\begin{array}{lrr}\text { Aoki } 2019 & 6 & 600 \\ \text { Han } 2013 & 1 & 89 \\ \text { Kwon } 2005 & 0 & 67 \\ \text { Nakamura } 2012 & 2 & 38 \\ \text { Ohnuki } 2017 & 0 & 13 \\ \text { Toyoda } 2019 & 11 & 383 \\ \text { Uchiyama 2015 } & 4 & 83 \\ \text { Subtotal (95\% Cl) } & & 1273\end{array}$

Heterogeneity: $\mathrm{Tau}^{2}=0.00 ; \mathrm{Chi}^{2}=0.39, \mathrm{df}=4(\mathrm{P}=0.98) ; \mathrm{I}^{2}=0 \%$

Test for overall effect: $Z=1.82(P=0.07)$

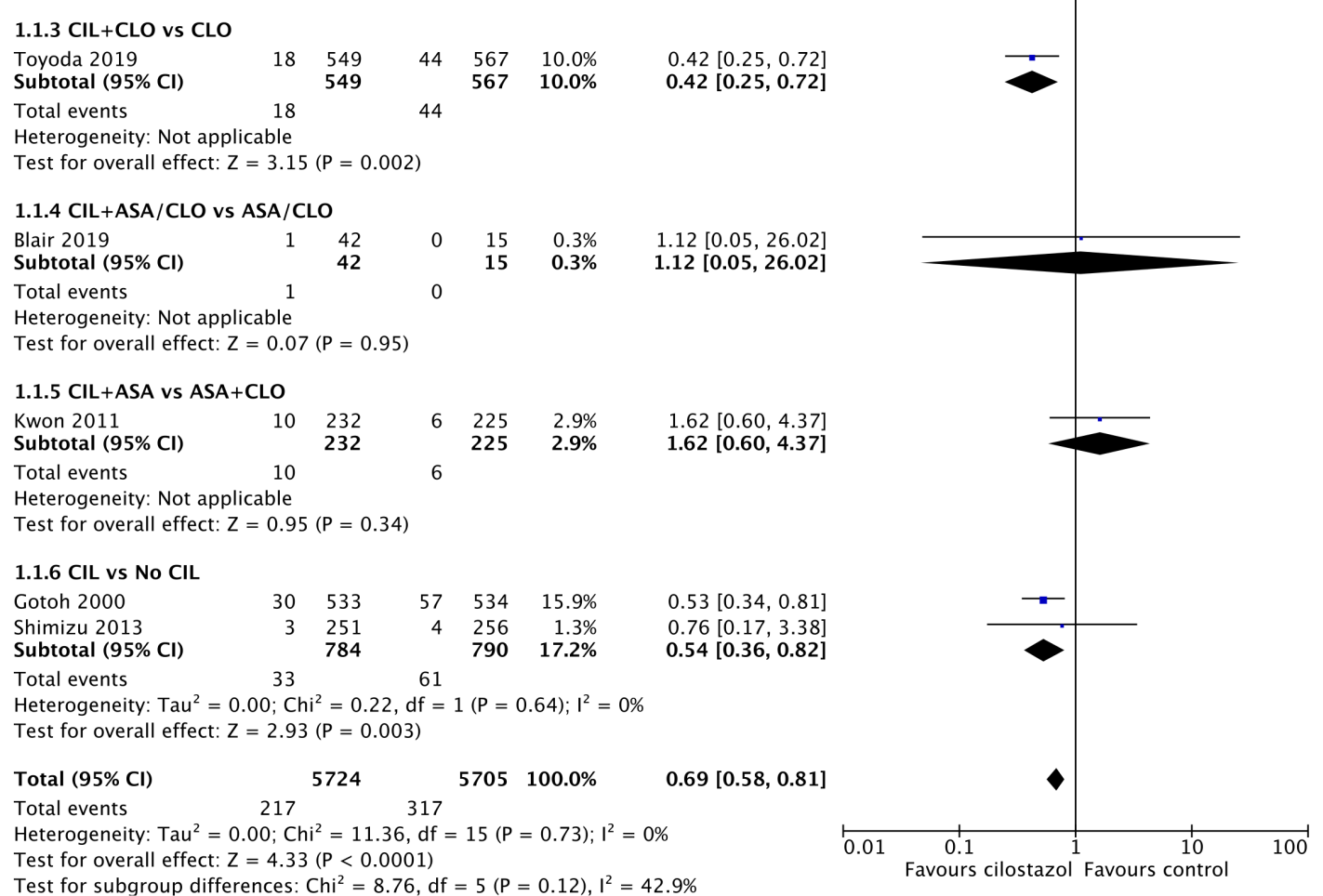

Figure 1 Forest plot depicting risk of ischaemic stroke recurrence. ASA, aspirin; CIL, cilostazol; CLO, clopidogrel; No CIL, placebo or best medical therapy.

\section{Major adverse cardiovascular events}

Most studies defined MACE as a composite of strokes, ICH, myocardial infarctions and vascular deaths. Meta-analysis of 13 trials (online supplemental data) revealed cilostazol significantly reduced the risk of MACE $(\mathrm{RR}=0.67,95 \% \mathrm{CI}$ 0.56 to $0.81, \mathrm{p}<0.0001)$. There was low heterogeneity across studies $\left(\mathrm{I}^{2}=0 \%\right)$.

Subgroup analysis based on specific antiplatelet regimens indicated moderate heterogeneity between antiplatelet regimens $\left(\mathrm{I}^{2}=54.6 \% ; \chi_{4}^{2}=8.82, \mathrm{p}=0.07\right)$. The greatest risk reduction was (1) CIL+ASA/CLO versus ASA/CLO ( $\mathrm{n}=1879$, from one trial ${ }^{38}$; followed by (2) CIL versus no CIL $(\mathrm{n}=1574)$. However, CIL versus ASA and CIL+ASA versus ASA did not significantly reduce the risk of MACE ( $\mathrm{p}=0.08$ and 0.75 , respectively). Similar to ischaemic stroke recurrence, CIL+ASA performed worse than ASA+CLO, but this effect was not statistically significant $(\mathrm{n}=457 ; \mathrm{RR}=1.45,95 \%$ CI 0.67 to $3.17, \mathrm{p}=0.35)$. When the specific type of antiplatelet was disregarded, cilostazol DAPT had a greater risk reduction $(\mathrm{n}=3497$; $\mathrm{RR}=0.58,95 \%$ CI 0.42 to $0.80, \mathrm{p}=0.0009$ ) than cilostazol SAPT ( $\mathrm{n}=2140 ; \mathrm{RR}=0.77,95 \%$ CI 0.57 to $1.03, \mathrm{p}=0.08$ ), both compared with an SAPT. Since one trial was able to considerably skew the results of CIL DAPT versus ASA SAPT, it suggests that the other studies are underpowered for MACE. 


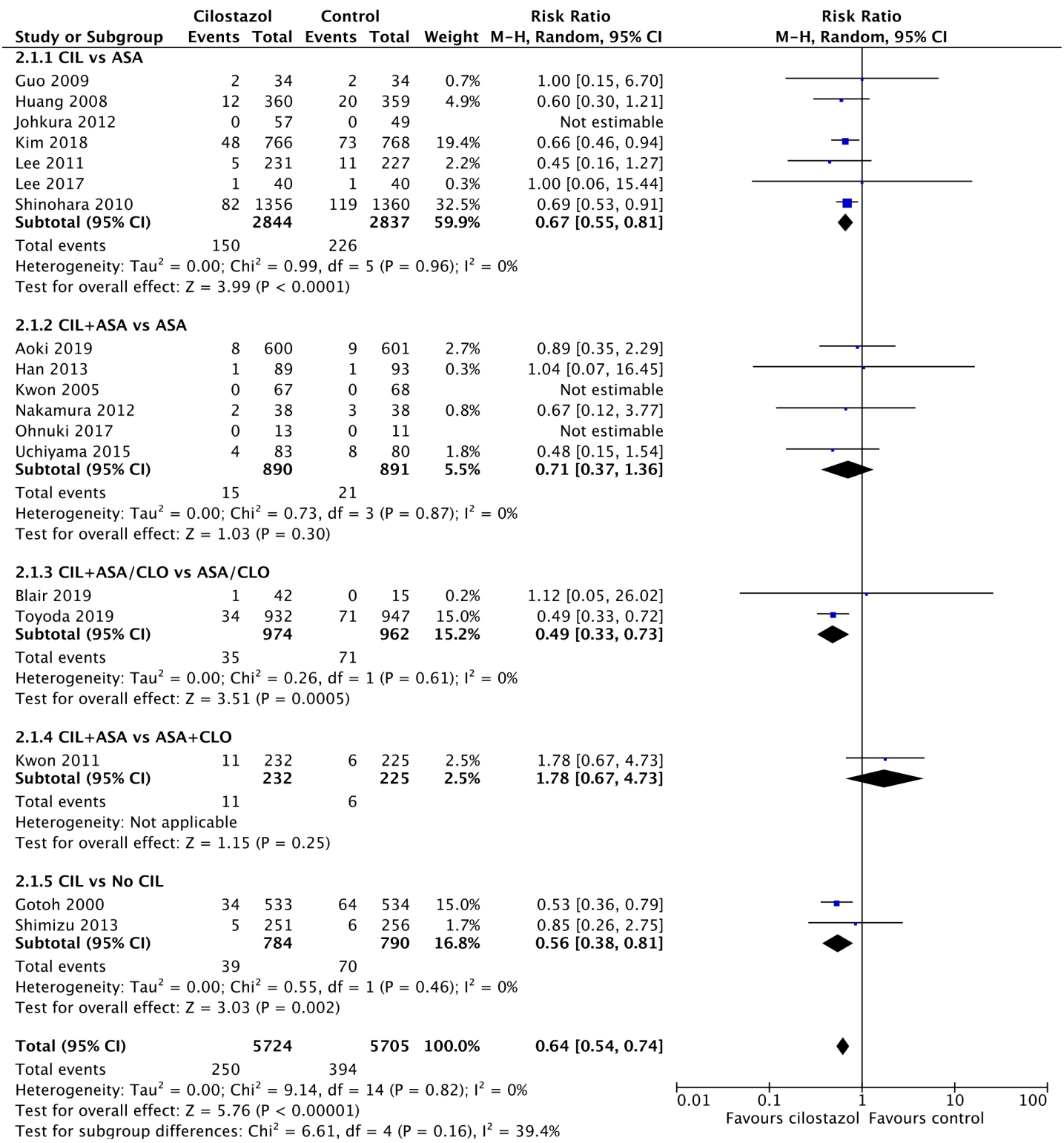

Figure 2 Forest plot depicting risk of any stroke recurrence. ASA, aspirin; CIL, cilostazol; CLO, clopidogrel; No CIL, placebo or best medical therapy.

\section{ADEs leading to treatment discontinuation}

Meta-analysis of 13 trials (online supplemental data) revealed cilostazol increased the risk of ADEs leading to treatment discontinuation ( $\mathrm{RR}=1.83,95 \% \mathrm{CI} 1.30$ to $2.59, \mathrm{p}=0.0006)$. There was high heterogeneity across studies $\left(\mathrm{I}^{2}=81 \%\right)$. In three studies, ${ }^{26} 2932$ the safety population comprising all participants who consumed the drug was used in place of the ITT population.

Subgroup analysis of the antiplatelet treatments demonstrated high heterogeneity among different regiments $\left(\mathrm{I}^{2}=82.9 \% ; \chi_{3}^{2}=17.58, \mathrm{p}=0.0005\right)$. The greatest statistically significant increase in relative risk occurred in the CIL+ASA/CLO versus ASA/CLO subgroup ( $\mathrm{n}=1936$; $\mathrm{RR}=5.59,95 \% \mathrm{CI} 3.04$ to 10.27 ), followed by the CIL versus No CIL subgroup ( $\mathrm{n}=1067$; RR=2.13, 95\% CI 1.43 to 3.16). There was no significant increase in ADEs leading to drug discontinuation in the CIL versus ASA and CIL+ASAversus ASA subgroup $(\mathrm{n}=5476$ and $1639, \mathrm{p}=0.11$ and 0.10 , respectively).

\section{Different administrative strategies}

Acute versus delayed administration for stroke

Acute/subacute stroke was defined as stroke within 72 hours of symptom onset. Based on the time from onset to randomisation or treatment, 4 studies comprising 2242 patients presented data on cilostazol administration during acute/ subacute stroke, while 14 studies comprising 9187 patients provided data for administration during chronic stroke (table 3). Cilostazol administration during the acute and chronic stroke phase demonstrated no significant difference in outcomes $\left(\mathrm{I}^{2} \leq 4.8 \% ; \mathrm{p}>0.05\right)$. 
Cilostazol Control

Risk Ratio

Study or Subgroup

Events Total Events Total Weight $\mathrm{M}-\mathrm{H}$, Random, 95\% $\mathrm{Cl}$ 3.1.1 CIL vs ASA

Guo 2009

Huang 2008

Johkura 2012

Kim 2018

Lee 2011

Lee 2017

Shinohara 2010

Subtotal $(95 \% \mathrm{CI})$

Total events

$\begin{array}{ll}0 & 34\end{array}$

$1 \quad 360$

(1)

Random, 95\%

Random, 95\% C

Heterogeneity: $\mathrm{Tau}^{2}=0.00 ; \mathrm{Chi}^{2}=1.69, \mathrm{df}=5(\mathrm{P}=0.89) ; \mathrm{I}^{2}=0 \%$

Test for overall effect: $Z=4.04(P<0.0001)$

3.1.2 CIL+ASA vs ASA

Aoki 2019

Han 2013

Kwon 2005

Nakamura 2012

Ohnuki 2017

Uchiyama 2015

Subtotal $(95 \% \mathrm{CI})$

Total events

$\begin{array}{rr}0 & 57 \\ 9 & 766\end{array}$

$0 \quad 231$

$0 \quad 40$

10
1356
2844

$\begin{array}{rrr}1 & 34 & 1.5 \% \\ 7 & 359 & 3.4 \%\end{array}$

$\begin{array}{ll}0 & 49\end{array}$

$\begin{array}{lll}18 \quad 768 & 23.5 \%\end{array}$

$2 \quad 227 \quad 1.6 \%$

$\begin{array}{lll}1 & 40 & 1.5 \%\end{array}$

$\begin{array}{lll}31 & 1360 & 29.4 \%\end{array}$

$\begin{array}{rr}1360 & 29.4 \% \\ 2837 & 60.8 \%\end{array}$

$0.33[0.01,7.91]$

$0.14[0.02,1.15]$

Not estimable

$0.50[0.23,1.11]$

$0.20[0.01,4.07]$

$0.33[0.01,7.95]$

$0.32[0.16,0.66]$

0.36 [0.22, 0.59 ]

Heterogeneity: $\mathrm{Tau}^{2}=0.85 ; \mathrm{Chi}^{2}=1.44, \mathrm{df}=1(\mathrm{P}=0.23) ; \mathrm{I}^{2}=30 \%$

Test for overall effect: $Z=0.25(P=0.80)$

3.1.3 CIL+ASA/CLO vs ASA/CLO

$\begin{array}{lrrrrrr}\text { Blair 2019 } & 0 & 42 & 0 & 15 & & \text { Not estimable } \\ \text { Toyoda 2019 } & 8 & 932 & 13 & 947 & 19.3 \% & 0.63[0.26,1.50] \\ \text { Subtotal }(\mathbf{9 5 \%} \mathbf{~ C l )} & & \mathbf{9 7 4} & & \mathbf{9 6 2} & \mathbf{1 9 . 3 \%} & \mathbf{0 . 6 3}[\mathbf{0 . 2 6}, \mathbf{1 . 5 0}] \\ \text { Total events } & 8 & & 13 & & & \end{array}$

Heterogeneity: Not applicable

Test for overall effect: $Z=1.05(P=0.29)$

3.1.4 CIL+ASA vs ASA+CLO

$\begin{array}{lllllll}\text { Kwon } 2011 & 1 & 232 & 1 & 225 & 1.9 \% & 0.97[0.06,15.41] \\ \text { Subtotal }(\mathbf{9 5 \%} \text { Cl) } & & 232 & & \mathbf{2 2 5} & \mathbf{1 . 9 \%} & \mathbf{0 . 9 7}[\mathbf{0 . 0 6}, \mathbf{1 5 . 4 1}] \\ \text { Total events } & 1 & & 1 & & & \end{array}$

Heterogeneity: Not applicable

Test for overall effect: $Z=0.02(P=0.98)$

3.1.5 CIL vs No CIL

Cotoh 2000

Shimizu 2013

Subtotal $(95 \% \mathrm{CI})$

Total events

$4 \quad 533$

251
784

6

$1 \quad 601 \quad 2.6 \%$

Not estimable

Not estimable

Not estimable

Not estimable

0.75 [0.08, 7.33]

Heterogeneity: $\mathrm{Tau}^{2}=0.00 ; \mathrm{Chi}^{2}=0.24, \mathrm{df}=1(\mathrm{P}=0.62) ; \mathrm{I}^{2}=0 \%$

Test for overall effect: $Z=0.75(P=0.45)$

$\begin{array}{lllll}\text { Total }(95 \% \mathrm{Cl}) & 5724 & 5705 & 100.0 \% & 0.46\end{array}\left[\begin{array}{l}0.31,0.68\end{array}\right.$

Total events $\quad 37 \quad 86$

Heterogeneity: $\mathrm{Tau}^{2}=0.00 ; \mathrm{Chi}^{2}=5.90, \mathrm{df}=11(\mathrm{P}=0.88) ; \mathrm{I}^{2}=0 \%$

Test for overall effect: $Z=3.94(P<0.0001)$

Test for subgroup differences: $\mathrm{Chi}^{2}=2.36, \mathrm{df}=4(\mathrm{P}=0.67), \mathrm{I}^{2}=0 \%$

$0.57[0.17,1.94]$

$1.02[0.14,7.18]$
$0.67[0.24,1.90]$

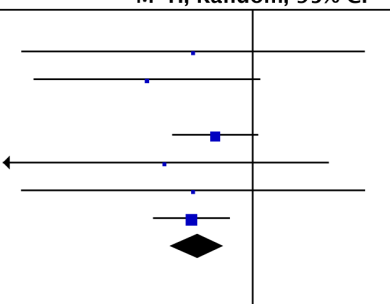

3]

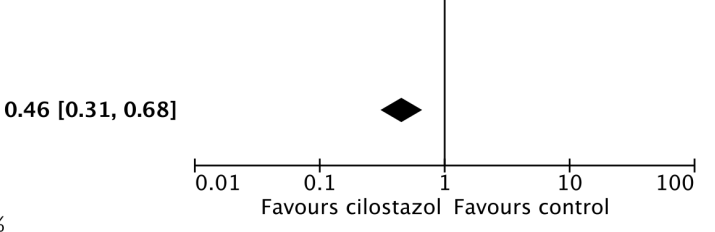

Figure 3 Forest plot depicting risk of intracranial haemorrhage. ASA, aspirin; CIL, cilostazol; CLO, clopidogrel; No CIL, placebo or best medical therapy.

\section{Short-term versus long-term treatment}

Long-term antiplatelet treatment was defined as drug administration for $\geq 3$ months. Three studies comprising 1282 patients administered short-term antiplatelet therapy, while 15 studies comprising 10147 patients administered treatment for $\geq 3$ months. For most outcomes (ischaemic stroke recurrence, any stroke recurrence, major haemorrhagic events and MACE), there was no significant difference in the efficacy/safety of cilostazol for short-term and long-term administration $\left(I^{2} \leq 3.0 \%\right)$. For mortality, there was insufficient events for short-term cilostazol administration to make a comparison. However, for ICH, there was moderate heterogeneity between short-term and long-term cilostazol administration $\left(\mathrm{I}^{2}=32.3 \% ; \chi_{1}^{2}=1.48\right.$, $\mathrm{p}=0.22)$. Long-term cilostazol administration reduces the risk of ICH $(\mathrm{RR}=0.44,95 \% \mathrm{CI} 0.30$ to 0.66 , $\mathrm{p}<0.0001)$, while short-term cilostazol administration was underpowered and seemed to confer no benefit ( $\mathrm{RR}=2.00,95 \%$ CI 0.18 to $22.03, \mathrm{p}=0.57$ ).

\section{Symptomatic ICAS}

Three studies comprising 755 patients included only patients with symptomatic ICAS. Two studies ${ }^{22} 25$ that did not specify whether ICAS was symptomatic or was associated with the infarct territory were excluded. For most outcomes, there was no significant difference between the symptomatic ICAS and mixed/other stroke subgroup. Most strikingly, in the ICAS subgroup, cilostazol administration is associated with an insignificant increase in risk of MACE ( $\mathrm{RR}=1.38,95 \% \mathrm{CI} 0.67$ to $2.85, \mathrm{p}=0.38$ ), compared with a statistically significant decrease in MACE risk in studies which did not exclusively recruit patients with symptomatic ICAS. Furthermore, there was no significant decrease in risk of ICAS progression or worsening 


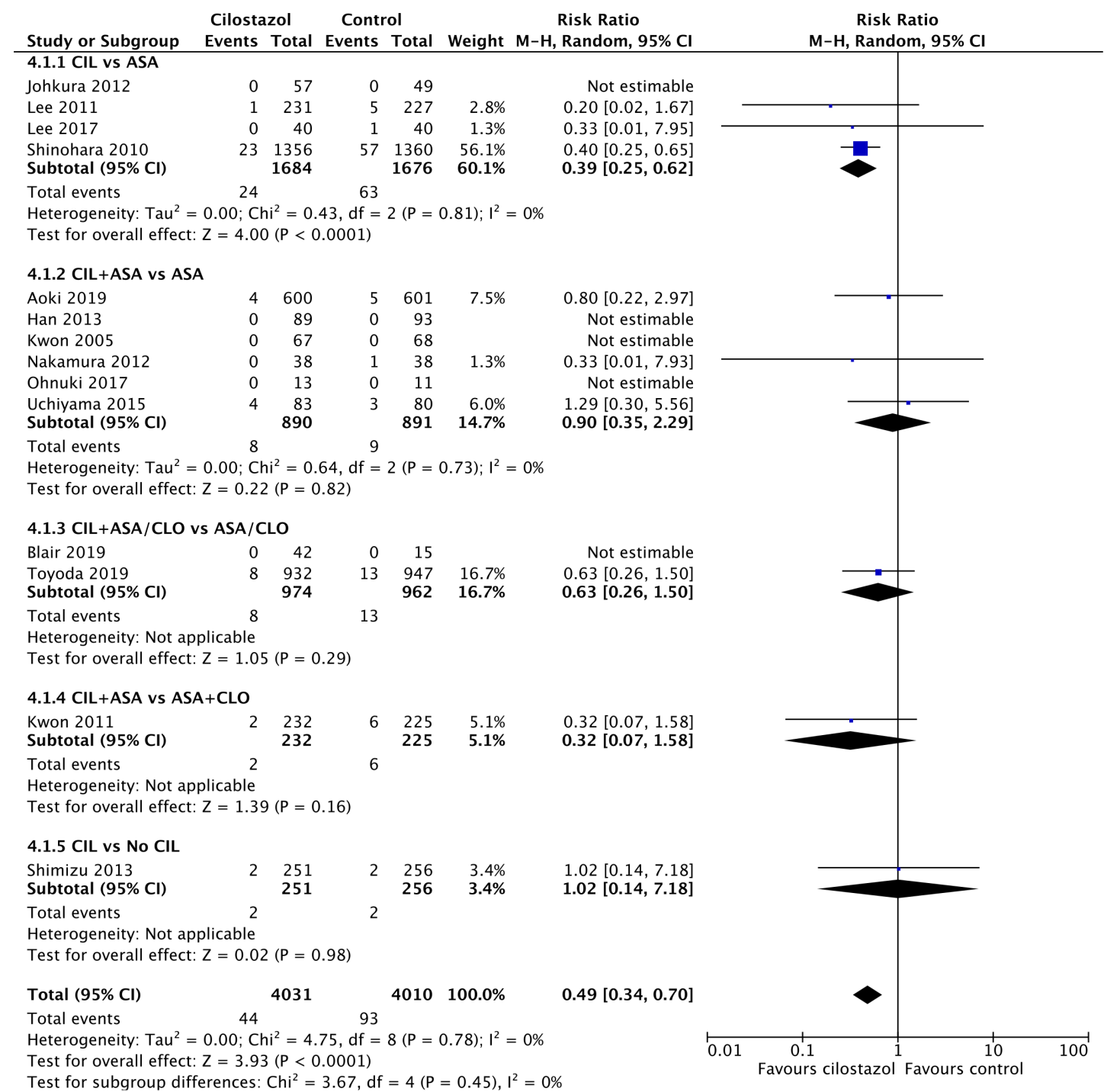

Figure 4 Forest plot depicting risk of major haemorrhagic events. ASA, aspirin; CIL, cilostazol; CLO, clopidogrel; No CIL, placebo or best medical therapy.

$(\mathrm{RR}=0.63,95 \% \mathrm{CI} 0.25$ to $1.58, \mathrm{p}=0.33)$ after cilostazol administration (online supplemental data).

\section{Further analyses}

Meta-regression of the mean or median: (1) duration of treatment or follow-up; (2) time from stroke onset to randomisation or treatment; or (3) proportion of patients with lacunar infarction did not reveal any significant effect on ischaemic stroke recurrence (online supplemental data). Funnel plots did not suggest publication bias for any outcome.

Using the GRADE tool, the quality of evidence was high for ischaemic stroke, any stroke, ICH, major haemorrhagic events and MACE; moderate for mortality and ADEs leading to treatment discontinuations; and low for good functional outcome.

\section{DISCUSSION}

Overall, cilostazol demonstrated good efficacy in secondary stroke prevention, significantly reducing the rates of ischaemic stroke recurrence, any stroke recurrence and MACE.

As a monotherapy, our updated meta-analysis confirmed that cilostazol was superior to aspirin. However, cilostazol monotherapy was not compared with clopidogrel. As combination therapy, the performance of cilostazol is promising. While bleeding outcomes did not increase when cilostazol was added to aspirin or clopidogrel, its efficacy in secondary ischaemic stroke prevention requires confirmation. Compared with aspirin monotherapy, the risk reduction of cilostazol DAPT was greater but just missed significance; we were not able to comment on its efficacy against clopidogrel monotherapy as it was compared with clopidogrel monotherapy in only one trial. ${ }^{38}$ In contrast to ASA+CLO combination therapy whose use is typically limited to 3 months or less, ${ }^{40}$ our results suggest that cilostazol combination therapy is a promising option for long-term secondary stroke prevention, similar to aspirin plus dipyridamole. ${ }^{41}$ Finally, when 


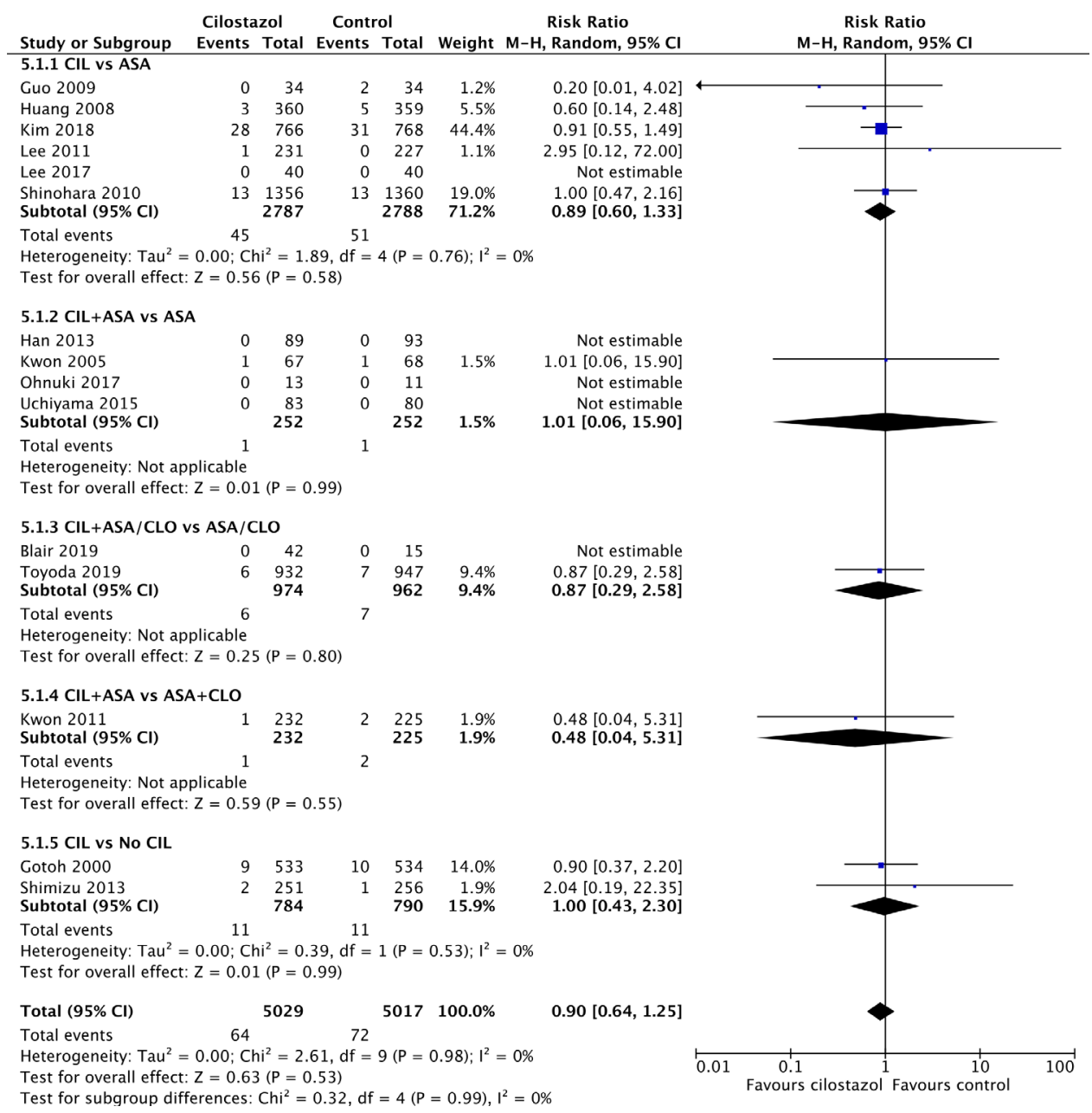

Figure 5 Forest plot depicting risk of mortality. ASA, aspirin; CIL, cilostazol; CLO, clopidogrel; No CIL, placebo or best medical therapy.

compared with other DAPT, CIL combination versus ASA+CLO was limited by wide CI and the availability of only one study ${ }^{31}$ (which demonstrated possible inferiority in stroke recurrence); the CIL+CLO option was not tested.

The 'No CIL' subgroup is a heterogeneous classification. One study ${ }^{24}$ compared cilostazol with placebo. Another study ${ }^{36}$ compared cilostazol with best medical therapy-both arms were subjected to a variety of both oral and intravenous antiplatelets, antithrombin, anticoagulants and/or free radical scavengers-without a placebo. Resultantly, it is difficult to comment on this subgroup.

Previous studies have demonstrated high mortality rates after a secondary stroke. ${ }^{42}$ Interestingly, despite a reduction in stroke recurrence and haemorrhagic complications, cilostazol did not significantly reduce mortality rates. One potential explanation is that studies were underpowered to assess the benefits of cilostazol administration on all-cause mortality. Although there were 644 'any stroke' recurrences, there were only 136 cases of mortality; given that the control mortality rate was only $1.44 \%$, the optimal information size was not met for an assumed $25 \%$ relative risk reduction. ${ }^{43}$
Additionally, the rate of good functional outcomes did not increase with cilostazol use. Apart from the fact that only four trials reported mRS scores, treatment was only administered for 3 or 6 months, with the latter achieving better functional outcomes. Future studies could assess the rates of mRS 0-1 with longer duration of antiplatelet administration.

Cilostazol use was associated with an increase in drug discontinuations due to ADEs, especially when administered as combination therapy. Common adverse effects included headaches, dizziness, palpitations, arrythmias and gastrointestinal disturbances. However, this analysis was complicated by high heterogeneity, which may be attributed to the wide variation in definition among trials. Some trials included vascular events and deaths, while others included medication non-compliance. Nevertheless, existing literature suggests that most of these adverse events are mild and temporary. ${ }^{10}$

Unexpectedly, cilostazol did not further reduce the rates of efficacy and safety outcomes in patients with symptomatic ICAS. This does not corroborate with existing literature, which suggests that the antiplatelet and vasodilating effect ${ }^{44}$ of cilostazol could prevent ICAS 


\begin{tabular}{|c|c|c|c|c|c|c|c|c|}
\hline \multicolumn{2}{|c|}{ Subgroup } & $\mathbf{N}$ & Cilostazol & Control & RR $(95 \% \mathrm{Cl})$ & $P$ value & $I^{2}(\%)$ & $\begin{array}{l}\text { Test for subgroup } \\
\text { differences }\end{array}$ \\
\hline \multicolumn{9}{|c|}{ Ischaemic stroke recurrence } \\
\hline \multirow[t]{2}{*}{ B } & CIL SAPT vs SAPT & 7 & $131 / 2844$ & $168 / 2837$ & $0.78(0.62-0.97)$ & 0.03 & 0 & \multirow{2}{*}{$\begin{array}{l}\chi_{3}^{2}=7.50, p=0.06 \\
I^{2}=60.0 \%\end{array}$} \\
\hline & CIL DAPT vs SAPT & 8 & $43 / 1864$ & $82 / 1853$ & $0.52(0.36-0.75)$ & 0.0005 & 0 & \\
\hline \multirow[t]{2}{*}{$\mathrm{C}$} & Stroke onset $<3$ days & 4 & $16 / 1120$ & $24 / 1122$ & $0.67(0.36-1.25)$ & 0.20 & 0 & \multirow{2}{*}{$\begin{array}{l}\chi_{1}^{2}=0.01, p=0.93 \\
I^{2}=0 \%\end{array}$} \\
\hline & Stroke onset $>3$ days & 14 & $201 / 4604$ & $293 / 4583$ & $0.69(0.56-0.84)$ & 0.0002 & 8 & \\
\hline \multirow[t]{2}{*}{$\mathrm{D}$} & Short term (<3 months) & 3 & $7 / 655$ & $8 / 627$ & $0.78(0.29-2.12)$ & 0.63 & 0 & \multirow{2}{*}{$\begin{array}{l}\chi_{1}^{2}=0.07, p=0.80 \\
I^{2}=0 \%\end{array}$} \\
\hline & Long term ( $\geq 3$ months) & 15 & $210 / 5069$ & $309 / 5078$ & $0.68(0.58-0.81)$ & $<0.0001$ & 0 & \\
\hline
\end{tabular}

\section{Any stroke recurrence}

\begin{tabular}{|c|c|c|c|c|c|c|c|c|}
\hline$A$ & Overall & 18 & $250 / 5724$ & $394 / 5705$ & $0.64(0.54-0.74)$ & $<0.00001$ & 0 & NA \\
\hline \multirow[t]{2}{*}{$B$} & Stroke onset $<3$ days & 4 & $20 / 1120$ & $29 / 1122$ & $0.70(0.39-1.23)$ & 0.21 & 0 & \multirow{2}{*}{$\begin{array}{l}\chi_{1}^{2}=0.11, p=0.75 \\
I^{2}=0 \%\end{array}$} \\
\hline & Stroke onset $>3$ days & 14 & $230 / 4604$ & $365 / 4583$ & $0.63(0.54-0.74)$ & $<0.00001$ & 0 & \\
\hline \multirow[t]{2}{*}{ C } & Short term ( $<3$ months) & 3 & $9 / 655$ & $9 / 627$ & $0.91(0.37-2.24)$ & 0.83 & 0 & \multirow{2}{*}{$\begin{array}{l}\chi_{1}^{2}=0.61, p=0.43, \\
I^{2}=0 \%\end{array}$} \\
\hline & Long term ( $\geq 3$ months) & 15 & $241 / 5069$ & $385 / 5078$ & $0.63(0.54-0.74)$ & $<0.00001$ & 0 & \\
\hline \multirow[t]{3}{*}{ D } & Symptomatic ICAS & 3 & $15 / 382$ & $14 / 373$ & $0.96(0.27-3.45)$ & 0.95 & 65 & \multirow{3}{*}{$\begin{array}{l}\chi_{2}^{2}=0.71, p=0.70 \\
I^{2}=0 \%\end{array}$} \\
\hline & $\mathrm{LACl}$ & 2 & $2 / 131$ & $1 / 108$ & $1.08(0.14-8.56)$ & 0.95 & 0 & \\
\hline & Others/mixed/unknown & 13 & $233 / 5211$ & $379 / 5224$ & $0.62(0.53-0.73)$ & $<0.00001$ & 0 & \\
\hline \multicolumn{9}{|c|}{ ntracranial haemorrhage } \\
\hline A & Overall & 18 & $37 / 5724$ & $86 / 5705$ & $0.46(0.31-0.68)$ & $<0.0001$ & 0 & NA \\
\hline \multirow[t]{2}{*}{$B$} & Stroke onset $<3$ days & 4 & $4 / 1120$ & $5 / 1122$ & $0.91(0.24-3.53)$ & 0.89 & 0 & \multirow{2}{*}{$\begin{array}{l}\chi_{1}^{2}=1.05, p=0.31 \\
I^{2}=4.8 \%\end{array}$} \\
\hline & Stroke onset $>3$ days & 14 & $33 / 4604$ & $81 / 4583$ & $0.43(0.29-0.65)$ & $<0.0001$ & 0 & \\
\hline \multirow[t]{2}{*}{ C } & Short term ( $<3$ months) & 3 & $2 / 655$ & $1 / 627$ & $2.00(0.18-22.03)$ & 0.57 & NA & \multirow{2}{*}{$\begin{array}{l}\chi_{1}^{2}=1.48, p=0.22, \\
I^{2}=32.3 \%\end{array}$} \\
\hline & Long term ( $\geq 3$ months) & 15 & $35 / 5069$ & $85 / 5078$ & $0.44(0.30-0.66)$ & $<0.0001$ & 0 & \\
\hline \multirow[t]{3}{*}{ D } & Symptomatic ICAS & 3 & $1 / 382$ & $3 / 373$ & $0.46(0.06-3.57)$ & 0.46 & 0 & \multirow{3}{*}{$\begin{array}{l}\chi_{1}{ }^{2}=0.00, p=1.00 \\
I^{2}=0 \%\end{array}$} \\
\hline & $\mathrm{LACl}$ & 2 & $0 / 131$ & $0 / 108$ & NA & NA & NA & \\
\hline & Others/mixed/unknown & 13 & $36 / 5211$ & $83 / 5224$ & $0.46(0.31-0.68)$ & 0.0001 & 0 & \\
\hline
\end{tabular}

\section{Major haemorrhagic events}

\begin{tabular}{|c|c|c|c|c|c|c|c|c|}
\hline A & Overall & 14 & $44 / 4031$ & $93 / 4010$ & $0.49(0.34-0.70)$ & $<0.0001$ & 0 & NA \\
\hline \multirow[t]{2}{*}{$\mathrm{B}$} & Stroke onset $<3$ days & 4 & $7 / 1120$ & $13 / 1122$ & $0.60(0.24-1.52)$ & 0.28 & 0 & \multirow{2}{*}{$\begin{array}{l}\chi_{1}{ }^{2}=0.23, p=0.63 \\
\mathrm{I}^{2}=0 \%\end{array}$} \\
\hline & Stroke onset $>3$ days & 10 & $37 / 2911$ & $80 / 2888$ & $0.47(0.32-0.69)$ & 0.0001 & 0 & \\
\hline \multirow[t]{2}{*}{$\mathrm{C}$} & Short term (<3 months) & 3 & $4 / 655$ & $5 / 627$ & $0.80(0.22-2.97)$ & 0.74 & NA & \multirow{2}{*}{$\begin{array}{l}\chi_{1}^{2}=0.59, p=0.44 \\
\mathrm{I}^{2}=0 \%\end{array}$} \\
\hline & Long term ( $\geq 3$ months) & 11 & $40 / 3376$ & $88 / 3383$ & $0.47(0.32-0.68)$ & $<0.0001$ & 0 & \\
\hline \multirow[t]{3}{*}{ D } & Symptomatic ICAS & 3 & $6 / 382$ & $9 / 373$ & $0.67(0.17-2.59)$ & 0.56 & 37 & \multirow{3}{*}{$\begin{array}{l}\chi_{1}{ }^{2}=0.24, p=0.62, \\
1^{2}=0 \%\end{array}$} \\
\hline & LACI & 2 & $0 / 131$ & $0 / 108$ & NA & NA & NA & \\
\hline & Others/mixed/unknown & 9 & $38 / 3518$ & $84 / 3529$ & $0.47(0.32-0.68)$ & $<0.0001$ & 0 & \\
\hline \multicolumn{9}{|c|}{ Mortality } \\
\hline A & Overall & 15 & $64 / 5029$ & $72 / 5017$ & $0.90(0.64-1.25)$ & 0.53 & 0 & NA \\
\hline \multirow[t]{2}{*}{$\mathrm{B}$} & Stroke onset $<3$ days & 2 & $3 / 482$ & $1 / 483$ & $2.33(0.34-15.82)$ & 0.39 & 0 & \multirow{2}{*}{$\begin{array}{l}\chi_{1}^{2}=0.98, p=0.32 \\
I^{2}=0 \%\end{array}$} \\
\hline & Stroke onset $>3$ days & 13 & $61 / 4547$ & $71 / 4534$ & $0.87(0.62-1.22)$ & 0.43 & 0 & \\
\hline
\end{tabular}


Table 3 Continued

\begin{tabular}{|c|c|c|c|c|c|c|c|c|}
\hline \multicolumn{2}{|c|}{ Subgroup } & \multirow{2}{*}{$\frac{\mathbf{N}}{2}$} & \multirow{2}{*}{$\begin{array}{c}\text { Cilostazol } \\
0 / 55\end{array}$} & \multirow{2}{*}{$\begin{array}{c}\text { Control } \\
0 / 26\end{array}$} & \multirow{2}{*}{$\begin{array}{l}\text { RR }(95 \% \text { Cl) } \\
\text { NA }\end{array}$} & \multirow{2}{*}{$\frac{P \text { value }}{\text { NA }}$} & \multirow{2}{*}{$\frac{I^{2}(\%)}{N A}$} & \multirow{2}{*}{$\begin{array}{l}\text { Test for subgroup } \\
\text { differences } \\
\text { NA }\end{array}$} \\
\hline $\mathrm{C}$ & Short term (<3 months) & & & & & & & \\
\hline & Long term ( $\geq 3$ months) & 13 & $64 / 4974$ & $72 / 4991$ & $0.90(0.64-1.25)$ & 0.53 & 0 & \\
\hline \multirow[t]{3}{*}{$\mathrm{D}$} & Symptomatic ICAS & 3 & $2 / 382$ & $3 / 373$ & $0.67(0.11-4.06)$ & 0.66 & 0 & \multirow{3}{*}{$\begin{array}{l}\chi_{1}^{2}=0.11, p=0.74 \\
1^{2}=0 \%\end{array}$} \\
\hline & $\mathrm{LACl}$ & 2 & $0 / 131$ & $0 / 108$ & NA & NA & NA & \\
\hline & Others/mixed/unknown & 10 & $62 / 4516$ & $69 / 4536$ & $0.91(0.65-1.27)$ & 0.58 & 0 & \\
\hline \multicolumn{9}{|c|}{ MACE } \\
\hline$A$ & Overall & 13 & $184 / 3826$ & $276 / 3842$ & $0.67(0.56-0.81)$ & $<0.0001$ & 0 & NA \\
\hline \multirow[t]{2}{*}{ B } & Stroke onset $<3$ days & 4 & $25 / 1120$ & $33 / 1122$ & $0.76(0.45-1.27)$ & 0.30 & 0 & \multirow{2}{*}{$\begin{array}{l}\chi_{1}^{2}=0.18, p=0.67, \\
1^{2}=0 \%\end{array}$} \\
\hline & Stroke onset $>3$ days & 9 & $159 / 2706$ & $243 / 2720$ & $0.67(0.52-0.86)$ & 0.002 & 20 & \\
\hline \multirow[t]{2}{*}{ C } & Short term (<3 months) & 2 & $12 / 613$ & $12 / 612$ & $1.00(0.45-2.21)$ & 1.00 & NA & \multirow{2}{*}{$\begin{array}{l}\chi_{1}^{2}=1.03, p=0.31 \\
1^{2}=3.0 \%\end{array}$} \\
\hline & Long term ( $\geq 3$ months) & 11 & $172 / 3213$ & $264 / 3230$ & $0.66(0.55-0.79)$ & $<0.0001$ & 0 & \\
\hline \multirow[t]{3}{*}{$\mathrm{D}$} & Symptomatic ICAS & 2 & $17 / 299$ & $12 / 293$ & $1.38(0.67-2.85)$ & 0.38 & 0 & \multirow{3}{*}{$\begin{array}{l}\chi_{2}^{2}=4.22, p=0.12 \\
1^{2}=52.6 \%\end{array}$} \\
\hline & LACI & 1 & $1 / 89$ & $1 / 93$ & $1.04(0.07-16.45)$ & 0.98 & NA & \\
\hline & Others/mixed/unknown & 10 & $166 / 3438$ & $263 / 3456$ & $0.64(0.53-0.77)$ & $<0.00001$ & 0 & \\
\hline
\end{tabular}

CIL, cilostazol; DAPT, dual antiplatelet therapy; ICAS, intracranial arterial stenosis; LACI, lacunar infarction; No CIL, placebo or best medical therapy; RR, risk ratio; SAPT, single antiplatelet therapy.

progression, which, unlike extracranial artery stenosis, cannot be equilibrised by collateral circulation. ${ }^{45}$

Subgroup analysis did not reveal any significant effect of stroke chronicity, or duration of treatment or follow-up, on efficacy and safety outcomes. However, the risk reduction of ICH is greater when cilostazol is administered long term, which could be due to the increase in incidence of ICH over time when aspirin is employed. Surprisingly, there was a lower overall rate of ischaemic stroke recurrence when cilostazol is administered during the acute/subacute phase $(1.78 \%)$ versus chronic phase $(5.38 \%)$ of ischaemic stroke. This may be attributed to a shorter duration of follow-up (14 days to 6 months) in the former subgroup; alternatively, these four trials excluded patients with NIHSS $\geq 8,16$ or 20 , which may reduce the risk of ischaemic stroke recurrence.

\section{Limitations}

All but one trial were performed in the East Asian population, thus the results of this meta-analysis may not be fully generalisable to other ethnicities. Additionally, the following analyses were underpowered: (1) mortality; (2) subgroup analysis for symptomatic ICAS; and (3) subgroup analysis for the duration of treatment. Moreover, there was moderate to high heterogeneity in the meta-analysis of (1) good functional outcome; and (2) ADEs leading to treatment discontinuation. Furthermore, due to the limited trials available, we were unable to compare the efficacy and safety of cilostazol with antiplatelet agents other than aspirin and clopidogrel. Finally, for one study, ${ }^{22}$ the time points at which the different outcomes were measured varied due to the limited information available.

\section{Implications for future research}

We identified knowledge gaps and areas for further research. For example, studies could perform trials on non-Asian populations. Furthermore, studies could compare the safety and efficacy profile of cilostazol with other antiplatelet regimens, in particular: (1) CIL versus CLO monotherapy; (2) CIL combination versus ASA+CLO, especially in the short term; and (3) newer antiplatelet agents, for instance, CIL versus ticagrelor (TIG) or CIL versus short-term ASA+TIG. While network meta-analyses may be performed to evaluate indirect evidence, further randomised controlled trials for direct comparisons are necessary.

\section{CONCLUSIONS}

Cilostazol SAPT and DAPT significantly reduced the risk of recurrent ischaemic stroke, any stroke and MACE but did not have a significant effect on functional outcomes. Cilostazol reduced ICH and major haemorrhagic complications compared with aspirin.

Contributors All coauthors made significant contributions to the planning, conduct, reporting and final approval of the study. CHT and AGRW are co-first authors.

Funding The authors have not declared a specific grant for this research from any funding agency in the public, commercial or not-for-profit sectors.

Competing interests None declared.

Patient consent for publication Not required.

Provenance and peer review Not commissioned; externally peer reviewed. Data availability statement Data are available upon reasonable request.

Open access This is an open access article distributed in accordance with the Creative Commons Attribution Non Commercial (CC BY-NC 4.0) license, which permits others to distribute, remix, adapt, build upon this work non-commercially, and license their derivative works on different terms, provided the original work is 
properly cited, appropriate credit is given, any changes made indicated, and the use is non-commercial. See: http://creativecommons.org/licenses/by-nc/4.0/.

\section{ORCID iDs}

Choon Han Tan http://orcid.org/0000-0002-5448-3365

Ching-Hui Sia http://orcid.org/0000-0002-2764-2869

Aloysius ST Leow http://orcid.org/0000-0003-3659-1650

Vijay Kumar Sharma http://orcid.org/0000-0002-8976-5696

Leonard LL Yeo http://orcid.org/0000-0002-4249-0402

Benjamin YQ Tan http://orcid.org/0000-0003-1824-9077

\section{REFERENCES}

1 Mohan KM, Wolfe CDA, Rudd AG, et al. Risk and cumulative risk of stroke recurrence: a systematic review and meta-analysis. Stroke 2011;42:1489-94.

2 Kauw F, Takx RAP, de Jong HWAM, et al. Clinical and imaging predictors of recurrent ischemic stroke: a systematic review and meta-analysis. Cerebrovasc Dis 2018;45:279-87.

3 Albright KC, Huang L, Blackburn J, et al. Racial differences in recurrent ischemic stroke risk and recurrent stroke case fatality. Neurology 2018;91:e1741-50

4 Powers WJ, Rabinstein AA, Ackerson T, et al. Guidelines for the early management of patients with acute ischemic stroke: 2019 update to the 2018 guidelines for the early management of acute ischemic stroke: a guideline for healthcare professionals from the American Heart Association/American Stroke Association. Stroke 2019;50:e344-418.

5 CAPRIE Steering Committee. A randomised, blinded, trial of clopidogrel versus aspirin in patients at risk of ischaemic events (CAPRIE). Lancet 1996;348:1329-39.

6 ESPRIT Study Group, Halkes PHA, van Gijn J, et al. Aspirin plus dipyridamole versus aspirin alone after cerebral ischaemia of arterial origin (ESPRIT): randomised controlled trial. Lancet 2006;367:1665-73.

7 Diener H-C, Bogousslavsky J, Brass LM, et al. Aspirin and clopidogrel compared with clopidogrel alone after recent ischaemic stroke or transient ischaemic attack in high-risk patients (MATCH): randomised, double-blind, placebo-controlled trial. Lancet 2004;364:331-7.

8 Bhatt DL, Fox KAA, Hacke W, et al. Clopidogrel and aspirin versus aspirin alone for the prevention of atherothrombotic events. $N$ Engl J Med 2006;354:1706-17.

9 Clagett GP, Sobel M, Jackson MR, et al. Antithrombotic therapy in peripheral arterial occlusive disease: the seventh ACCP conference on antithrombotic and thrombolytic therapy. Chest 2004;126:609s-26.

10 Noma K, Higashi Y. Cilostazol for treatment of cerebral infarction. Expert Opin Pharmacother 2018;19:1719-26.

11 O'Donnell ME, Badger SA, Sharif MA, et al. The vascular and biochemical effects of cilostazol in patients with peripheral arterial disease. J Vasc Surg 2009;49:1226-34

12 Wang Y, Liu M, Pu C. 2014 Chinese guidelines for secondary prevention of ischemic stroke and transient ischemic attack. Int $J$ Stroke 2017;12:302-20.

13 Kim JS, Kwon SU, Uchiyama S. Cilostazol research in Asia: can it be applied to European and American patients? Int J Stroke 2015;10:1-9.

14 Toyoda K, Inoue M, Koga M. Small but steady steps in stroke medicine in Japan. J Am Heart Assoc 2019;8:e013306.

15 Kern R, Nagayama M, Toyoda K, et al. Comparison of the European and Japanese guidelines for the management of ischemic stroke. Cerebrovasc Dis 2013;35:402-18.

16 Tan L, Margaret B, Zhang JH, et al. Efficacy and safety of cilostazol therapy in ischemic stroke: a meta-analysis. J Stroke Cerebrovasc Dis 2015;24:930-8.

17 Kim SM, Jung J-M, Kim BJ, et al. Cilostazol mono and combination treatments in ischemic stroke: an updated systematic review and meta-analysis. Stroke 2019:50:3503-11.

18 McHutchison C, Blair GW, Appleton JP, et al. Cilostazol for secondary prevention of stroke and cognitive decline: systematic review and meta-analysis. Stroke 2020;51:2374-85.

19 Moher D, Liberati A, Tetzlaff J, et al. Preferred reporting items for systematic reviews and meta-analyses: the PRISMA statement. BMJ 2009;339:b2535.

20 Sterne JAC, Savović J, Page MJ, et al. RoB 2: a revised tool for assessing risk of bias in randomised trials. BMJ 2019;366:14898.
21 Guyatt GH, Oxman AD, Vist GE, et al. GRADE: an emerging consensus on rating quality of evidence and strength of recommendations. BMJ 2008;336:924-6.

22 Aoki J, Iguchi Y, Urabe T, et al. Acute aspirin plus cilostazol dual therapy for noncardioembolic stroke patients within 48 hours of symptom onset. J Am Heart Assoc 2019;8:e012652.

23 Blair GW, Appleton JP, Flaherty K, et al. Tolerability, safety and intermediary pharmacological effects of cilostazol and isosorbide mononitrate, alone and combined, in patients with lacunar ischaemic stroke: the LACunar Intervention-1 (LACl-1) trial, a randomised clinical trial. EClinicalMedicine 2019;11:34-43.

24 Gotoh F, Tohgi H, Hirai S, et al. Cilostazol stroke prevention study: a placebo-controlled double-blind trial for secondary prevention of cerebral infarction. J Stroke Cerebrovasc Dis 2000;9:147-57.

25 Guo J-J, Xu E, Lin Q-Y, et al. Effect of cilostazol on cerebral arteries in secondary prevention of ischemic stroke. Neurosci Bull 2009;25:383-90.

26 Han SW, Lee S-S, Kim SH, et al. Effect of cilostazol in acute lacunar infarction based on pulsatility index of transcranial Doppler (ECLIPse): a multicenter, randomized, double-blind, placebocontrolled trial. Eur Neurol 2013;69:33-40.

27 Huang Y, Cheng Y, Wu J, et al. Cilostazol as an alternative to aspirin after ischaemic stroke: a randomised, double-blind, pilot study. Lancet Neurol 2008;7:494-9.

28 Johkura K, Yoshida TN, Kudo Y, et al. Cilostazol versus aspirin therapy in patients with chronic dizziness after ischemic stroke. Clin Neurol Neurosurg 2012;114:876-80.

29 Kim BJ, Lee E-J, Kwon SU, et al. Prevention of cardiovascular events in Asian patients with ischaemic stroke at high risk of cerebra haemorrhage (PICASSO): a multicentre, randomised controlled trial. Lancet Neurol 2018;17:509-18.

30 Kwon SU, Cho Y-J, Koo J-S, et al. Cilostazol prevents the progression of the symptomatic intracranial arterial stenosis: the multicenter double-blind placebo-controlled trial of cilostazol in symptomatic intracranial arterial stenosis. Stroke 2005;36:782-6.

31 Kwon SU, Hong K-S, Kang D-W, et al. Efficacy and safety of combination antiplatelet therapies in patients with symptomatic intracranial atherosclerotic stenosis. Stroke 2011;42:2883-90.

32 Lee Y-S, Bae H-J, Kang D-W, et al. Cilostazol in acute ischemic stroke treatment (CAIST trial): a randomized double-blind noninferiority trial. Cerebrovasc Dis 2011;32:65-71.

33 Lee S-J, Lee JS, Choi MH, et al. Cilostazol improves endothelial function in acute cerebral ischemia patients: a double-blind placebo controlled trial with flow-mediated dilation technique. BMC Neurol 2017:17:169.

34 Nakamura T, Tsuruta S, Uchiyama S. Cilostazol combined with aspirin prevents early neurological deterioration in patients with acute ischemic stroke: a pilot study. J Neurol Sci 2012;313:22-6.

35 Ohnuki Y, Ohnuki Y, Kohara S, et al. Dual therapy with aspirin and cilostazol may improve platelet aggregation in noncardioembolic stroke patients: a pilot study. Intern Med 2017;56:1307-13.

36 Shimizu H, Tominaga T, Ogawa A, et al. Cilostazol for the prevention of acute progressing stroke: a multicenter, randomized controlled trial. J Stroke Cerebrovasc Dis 2013;22:449-56.

37 Shinohara Y, Katayama Y, Uchiyama S, et al. Cilostazol for prevention of secondary stroke (CSPS 2): an aspirin-controlled, double-blind, randomised non-inferiority trial. Lancet Neurol 2010;9:959-68.

38 Toyoda K, Uchiyama S, Yamaguchi T, et al. Dual antiplatelet therapy using cilostazol for secondary prevention in patients with high-risk ischaemic stroke in Japan: a multicentre, open-label, randomised controlled trial. Lancet Neurol 2019;18:539-48.

39 Uchiyama S, Sakai N, Toi S, et al. Final results of Cilostazol-Aspirin therapy against recurrent stroke with intracranial artery stenosis (CATHARSIS). Cerebrovasc Dis Extra 2015;5:1-13.

40 Rahman H, Khan SU, Nasir F, et al. Optimal duration of aspirin plus clopidogrel after ischemic stroke or transient ischemic attack. Stroke 2019;50:947-53.

41 Hackam DG, Spence JD. Antiplatelet therapy in ischemic stroke and transient ischemic attack. Stroke 2019;50:773-8.

42 Singh R-J, Chen S, Ganesh A, et al. Long-term neurological, vascular, and mortality outcomes after stroke. Int J Stroke 2018;13:787-96.

43 Guyatt GH, Oxman AD, Kunz R, et al. GRADE guidelines 6. Rating the quality of evidence-imprecision. J Clin Epidemiol 2011;64:1283-93.

44 Weintraub WS. The vascular effects of cilostazol. Can J Cardiol 2006;22:56B-60.

$45 \mathrm{Kim}$ JS, Bang OY. Medical treatment of intracranial atherosclerosis: an update. J Stroke 2017;19:261-70. 